Original Research

\title{
Storable Energy Production from Wind over Water
}

Max F. Platzer ${ }^{*}$, Nesrin Sarigul-Klijn

Mechanical and Aerospace Engineering Department, iPGS (innovative Power Generations Systems) Research Group, University of California Davis, 2132 Bainer Drive, Davis CA 95616-5294, USA; EMails: mfplatzer@gmail.com; nsarigulklijn@ucdavis.edu

* Correspondence: Max F. Platzer; E-Mail: mfplatzer@gmail.com

Academic Editor: Alfonso Chinnici

Special Issue: Hydrogen Energy: Sustainable Production, Storage and Utilisation

Journal of Energy and Power Technology

2020, volume 2 , issue 2

doi:10.21926/jept.2002005
Received: January 28, 2020

Accepted: April 17, 2020

Published: April 29, 2020

\begin{abstract}
The current status of a project is described which aims to demonstrate the technical and economic feasibility of converting the vast wind energy available over the globe's oceans and lakes into storable energy. To this end, autonomous high-performance sailing ships are equipped with hydrokinetic turbines whose output is stored either in electric batteries or is fed into electrolysers to produce hydrogen which then is compressed and stored in tanks. In the present paper, the previous analytical studies which showed the potential of this "energy ship concept" are summarized and progress on its hardware demonstration is reported, involving the conversion of a model sailboat to autonomous operation. The paper concludes with a discussion of the potential of this concept to achieve the IPCC-mandated requirement of reducing the global CO2 emissions by about $45 \%$ by 2030 , reaching net zero by 2050 .
\end{abstract}

\section{Keywords}

Aero-hydronautical engineering; sailing ships; hydrokinetic turbines; electrolysis

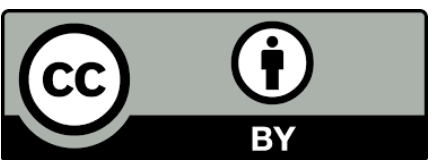

(C) 2020 by the author. This is an open access article distributed under the conditions of the Creative Commons by Attribution License, which permits unrestricted use, distribution, and reproduction in any medium or format, provided the original work is correctly cited. 


\section{Introduction}

The 2018 Special Report of the Intergovernmental Panel on Climate Change (IPCC) states that the global net anthropogenic carbon dioxide emissions need to decline by about $45 \%$ from 2010 levels by 2030, reaching net zero by 2050 if the global warming is to be limited to 1.5 degrees Celsius. In his recent addresses to the United Nations General Assembly in New York in September 2019 and COP25 in Madrid in December 2019 the United Nations Secretary General Antonio Guterres stressed the need for the declaration of a global climate emergency. Unfortunately, COP25 yielded no consensus on how to achieve these IPCC requirements.

Clearly, the global renewable energy resources need to be ranked by availability and exploitability in order to arrive at a firm conclusion whether the IPCC goals can be met. To this end, it should be obvious that the global wind resources must include the winds over the oceans since water covers 70 percent of the globe's surface. The quantity, strength and persistence of the ocean winds far exceed the available land and offshore wind power. Therefore, it raises the question whether the wind over water can be converted into storable energy to meet the IPCC requirement.

The engineering challenge for the near future therefore is the search for effective and efficient methods to convert the vast ocean wind power into usable power. This calls for the combination of aero-hydronautical engineering principles and methods with power engineering principles and methods to tap into the global ocean wind power. There has been a great reluctance to think of a power generator as anything but a machine that requires a firm footing. The need to find stronger winds has driven wind turbines offshore and there are now attempts underway to mount them on floatable structures. The next logical step therefore is to make the floatable structure movable so that it can be placed in high-wind ocean areas and moved quickly away from upcoming storms. This suggests to capture the wind with sails and to propel sailing ships at sufficiently large speeds to enable power production with relatively small ship-mounted hydro-turbines, thereby converting sailing ships into "energy ships".

The basic concept seems to have been first proposed in 1982 in a US patent by Robert E. Salomon [1], followed by patents disclosed by Meller [2] in 2006, Gizara [3] in 2007 and Holder [4] in 2008, but no analysis of these ideas in a scientific paper was published. In 2009 the authors [5] proposed the use of conventional sailing ships to produce hydrogen, while at about the same time Kim and Park [6] proposed parafoil-pulled ships equipped with hydrokinetic turbines. In 2015 Siddapaji and Turner [7] presented a design for a hydrokinetic turbine suitable for energy ship operation and in 2017 Gilloteaux and Babarit [8] presented a preliminary design of a wind driven vessel for hydrogen production. In 2018 Babarit et al. [9] followed up with a techno-economic feasibility study of fleets of offshore hydrogen-producing wind energy converters.

The basic system, proposed in reference [5], is shown in Figure 1. A hydrokinetic turbine is attached to the sailing ship for the generation of elelctricity which can either be stored in electric batteries, as shown in Figure 1a, or it can be fed into a desalinator and electrolyser to desalinate the seawater and to extract hydrogen for compression and storage in tanks, as shown in Figure $1 \mathrm{~b}$. The battery storage method is likely to be the most efficient one for boats operating close to shore due to the short round trip times needed for the periodic delivery of charged batteries and the pickup of empty ones. The hydrogen storage method, on the other hand, is more suitable for operation far from shore. In this case, the energy ships periodically transfer the hydrogen tanks to 
special tankers for transportation of the hydrogen tanks back to shore to power hydrogen fuel cell equipped vehicles or to be used for heating and cooking or to be reconverted into electricity via fuel cells or special hydrogen power plants (Figure 1b). This wind energy conversion system was analysed by Pelz et al [10] using the method of multi-pole system analysis (MPSA) developed by Holl and Pelz [11] and Holl et al [12]. This method involves four steps: (i) modelling, (ii) analysis, (iii) optimization and (iv) sensitivity analysis. It allows to understand the interactions of multiple input and output quantities.

\section{(a) Electric Battery Energy Storage}

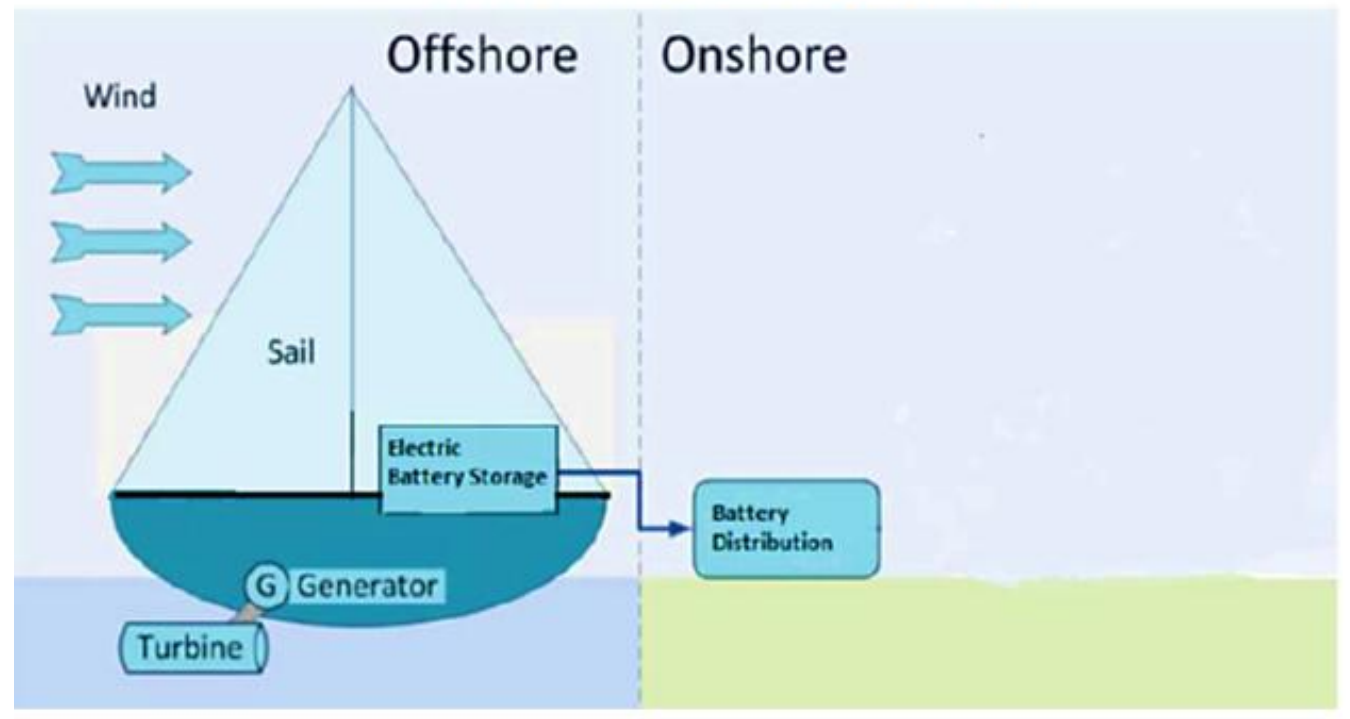

(b) Hydrogen Production and Delivery

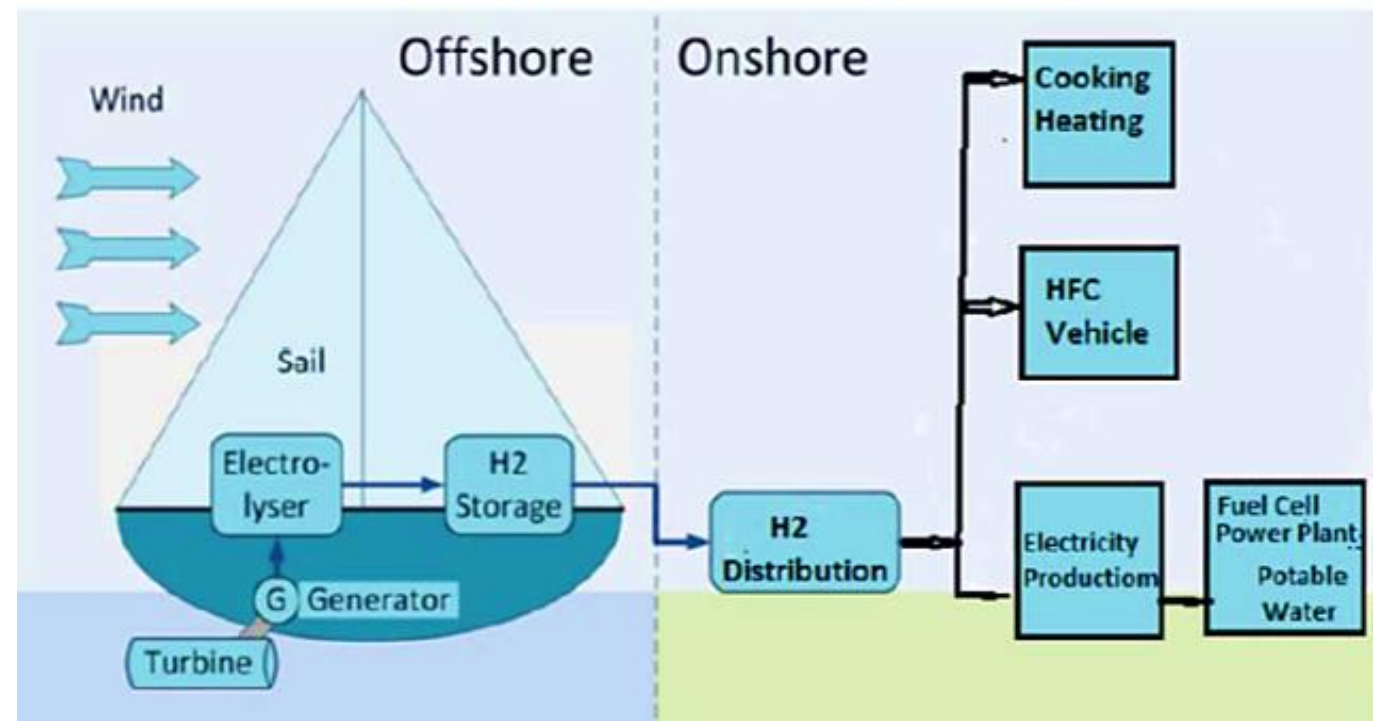

Figure 1 The energy ship concept option (a) Electric Battery Energy Storage; (b) Hydrogen Production and Delivery.

The application to the energy ship involves the effect of and interaction between the lift of the sail(s), the ship's hydrodynamic and aerodynamic drag and its wetted area, the turbine area and the turbine's axial induction factor. Pareto optimization then allows to find the optimal coefficient of performance. The results of this energetic optimization are shown in Figure 2, Figure 3, Figure 4 
of reference [10], where the influence of the turbine area, lift and drag and wetted area, respectively, are plotted. This MPSA analysis was further extended to include the economical optimization by using the available ship, turbine, desalinator, electrolyser, hydrogen compressor and tank costs as well as the operation \& maintenance and the investment costs. These details are described in references [10-12]. Assuming plausible values for the above parameters the analysis yielded a power output of $13 \mathrm{~kW}$ for a sailboat with a sail area of $50 \mathrm{~m}^{2}$ and $1 \mathrm{MW}$ for a ship with a sail area of $3200 \mathrm{~m}^{2}$ in winds of $10 \mathrm{~m} / \mathrm{s}$. In addition, Holl et al [13] performed a sensitivity analysis of this techno-economically optimal wind energy converter. Further details about the energy ship concept are given in references [14-17].

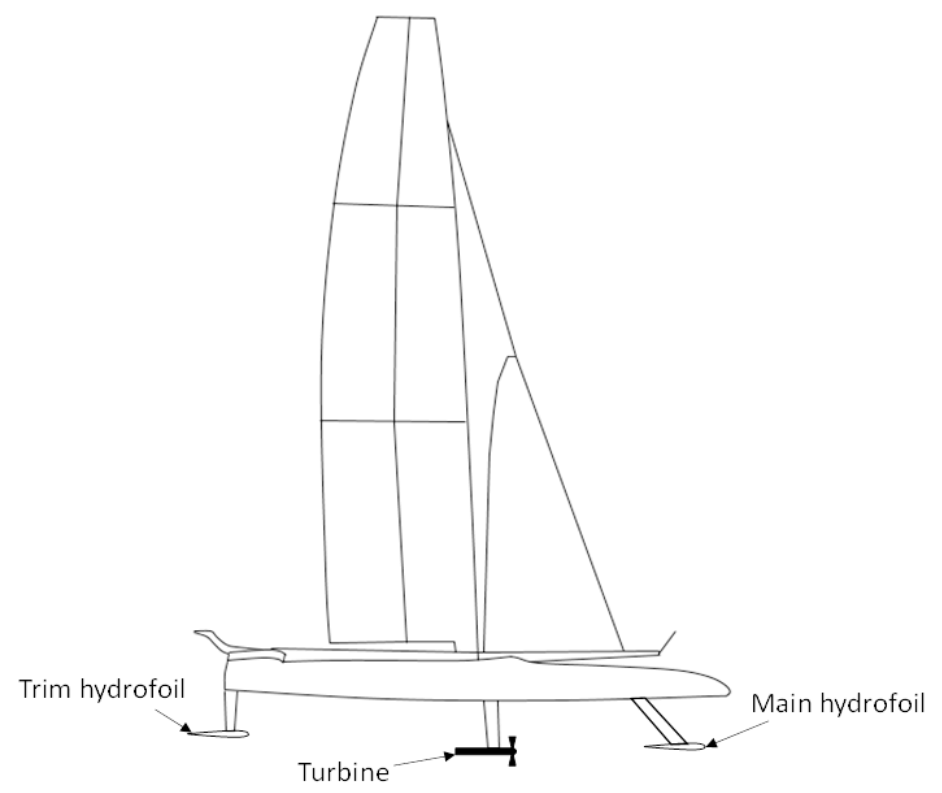

Figure 2 Autonomous hydrofoil power boat.

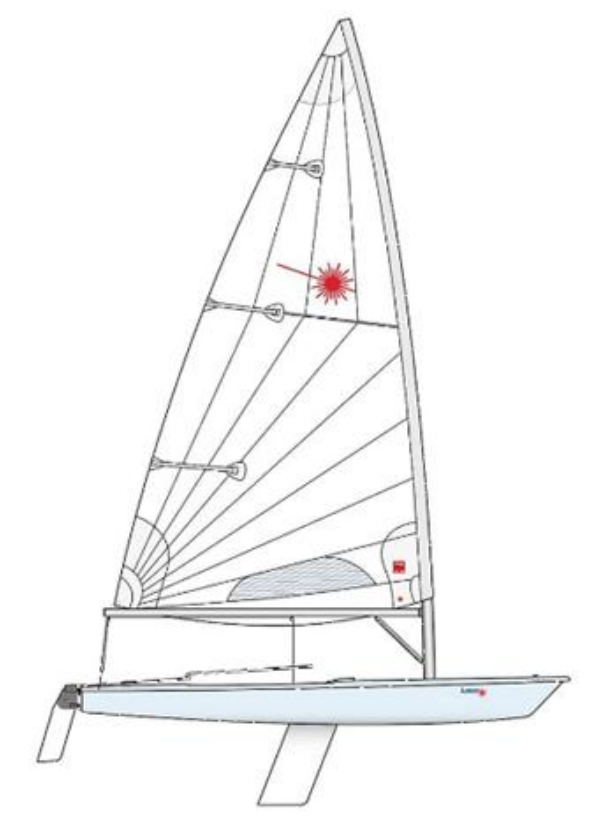

Figure 3 LASER sailboat (Image from Annapolis Performance Sailing) https://www.apsltd.com/lp-laser-sailboat-race.html). 
These techno-economic studies showed the potential of using sailing ships to convert the wind over the oceans and lakes into storable energy. It remains to translate these analytical studies into hardware by demonstrating a prototype energy ship within the constraints of a very limited budget. Since autonomous operation is a necessary condition for economical energy ship operations the next logical development step is its demonstration on an affordable boat. Model sailboats appear to be suitable test beds before moving to increasingly larger sailboats and sailing ships. They make it possible to demonstrate the optimal sailing mode predicted in the analytical studies. Therefore, the purpose of the present paper is twofold: (i) to highlight the operational mode of ship and turbine for optimal power production (ii) to document the development status of a small-scale technology demonstrator for autonomous energy ship operations.

\section{Optimal Energy Ship Design and Operational Considerations}

The energy ship concept requires the use of a relatively large sail area to overcome the drag of the hydrokinetic turbine and of the ship. The turbine drag cannot be reduced below the minimum required to generate power. However, the ship hydrodynamic resistance can be greatly reduced by the use of modern hydrofoil technology in combination with modern sail technology. Therefore, the ultimate design of an optimal energy ship will be a hydrofoil boat as shown in Figure 2 . However, a cost-effective first step toward hardware demonstration is the conversion of a small displacement boat to autonomous operation to assess the fidelity of the theoretical predictions and to provide the data necessary for the building of larger-scale ships. Therefore, the model LASER sailboat, shown in Figure 3, was selected for conversion to autonomous navigation and control. Optimal power generation requires a course heading into the wind at a true wind angle (defined in Figure 4) of approximately 100 to 110 degrees. Furthermore, for optimal power generation the turbine operating characteristics are quite different from the optimal condition for stationary turbines. These findings can be deduced from the analysis shown below.

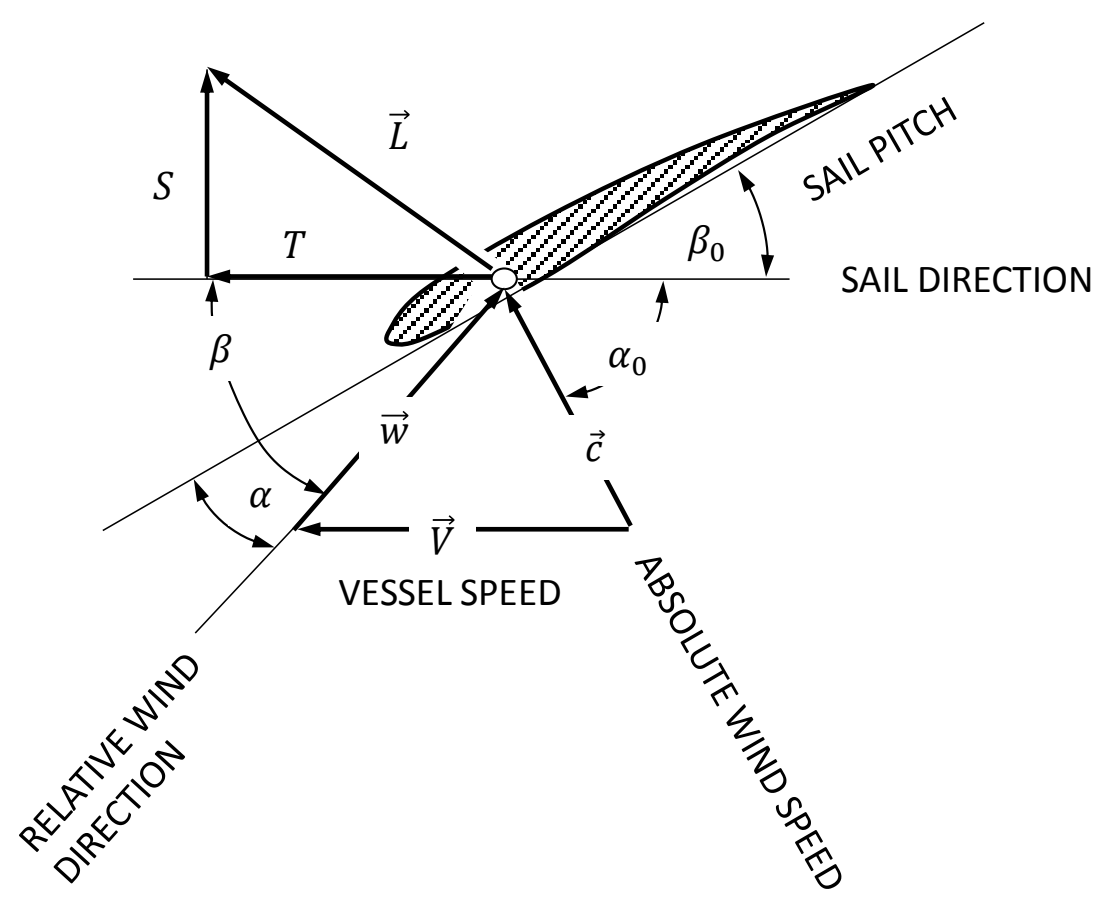

Figure 4 Forces acting on the rigid sail of a sail boat [10] 
Since the total ship drag must be balanced by the sail thrust, the total aerodynamic force $L$ on the sail (represented by an airfoil) has a component T pointing forward which provides the thrust to move the boat forward in a specific direction. Sailing with the speed $V$ at an angle $\alpha_{0}$ to the absolute (true) wind speed c exposes the boat to an apparent wind speed $w$ at angle $\beta$. It can be readily seen that the boat cannot sail directly into the wind, but needs to tack alternately to port or starboard in order to reach a point in the wind direction.

The use of sailing ships for power production by means of attached hydrokinetic turbines necessitates the maximization of the sail thrust and the minimization of the ship drag because the power production from the hydrokinetic turbines generates an unavoidable drag force. For this reason, it is crucial to determine the sailing mode that maximizes the sail thrust. As can be seen from Figure 4, the thrust force is given as a trigonometric function of the lift force

$$
T=\sin \beta \frac{\rho_{g}}{2} A c_{L}(\alpha) w^{2}
$$

where $A$ denotes the sail area, $\rho_{g}$ is the air density, $\beta$ denotes the relative wind direction, $w$ is the relative wind speed and $c_{L}$ is the lift coefficient, which is a function of the angle of attack $\alpha$. The cosine rule gives a relation between the velocities at the sail section

$$
u^{2}=V^{2}+c^{2}-2 V c \cos \alpha_{0}
$$

where $c$ denotes the absolute wind velocity and $\alpha_{0}$ the absolute wind direction. The absolute wind velocity is the vector sum of the relative wind and the vessel speed

$$
\vec{c}=\vec{V}+\vec{w}
$$

By introducing the ship-to-wind speed ratio $s=V / c$, the dimensionless thrust is given by

$$
\mathrm{Ct}=\frac{T}{\frac{\rho g}{2} c^{2} A}=\sin \beta c_{L}\left(s^{2}+1-2 s \cos \alpha_{0}\right)
$$

or after re-expressing the above equation by a function of $\alpha_{0}$ only using the relationship

$$
\begin{gathered}
w / c=\sin \alpha_{0} / \sin \beta \\
\mathrm{Ct}=C_{L}\left(\sin \alpha_{0}\right) \sqrt{s^{2}+1-2 s \cos \alpha_{o}} \text { or } \mathrm{Ct}=C_{L} \sqrt{\left(1-\cos ^{2} \alpha_{o}\right)\left(s^{2}+1-2 s \cos \alpha_{o}\right)}
\end{gathered}
$$

Differentiation with respect to $\cos \alpha_{0}$ and equating to zero then yields the absolute wind angle for maximum thrust as a function of the dimensionless ship speed, displayed in Figure 5. It is seen that the absolute wind angle increases from 90 degrees at zero ship speed to 106.90 at half wind speed and to 109.50 at full wind speed and then declines again toward 90 degrees as the ship speed increases to multiples of the wind speed. 


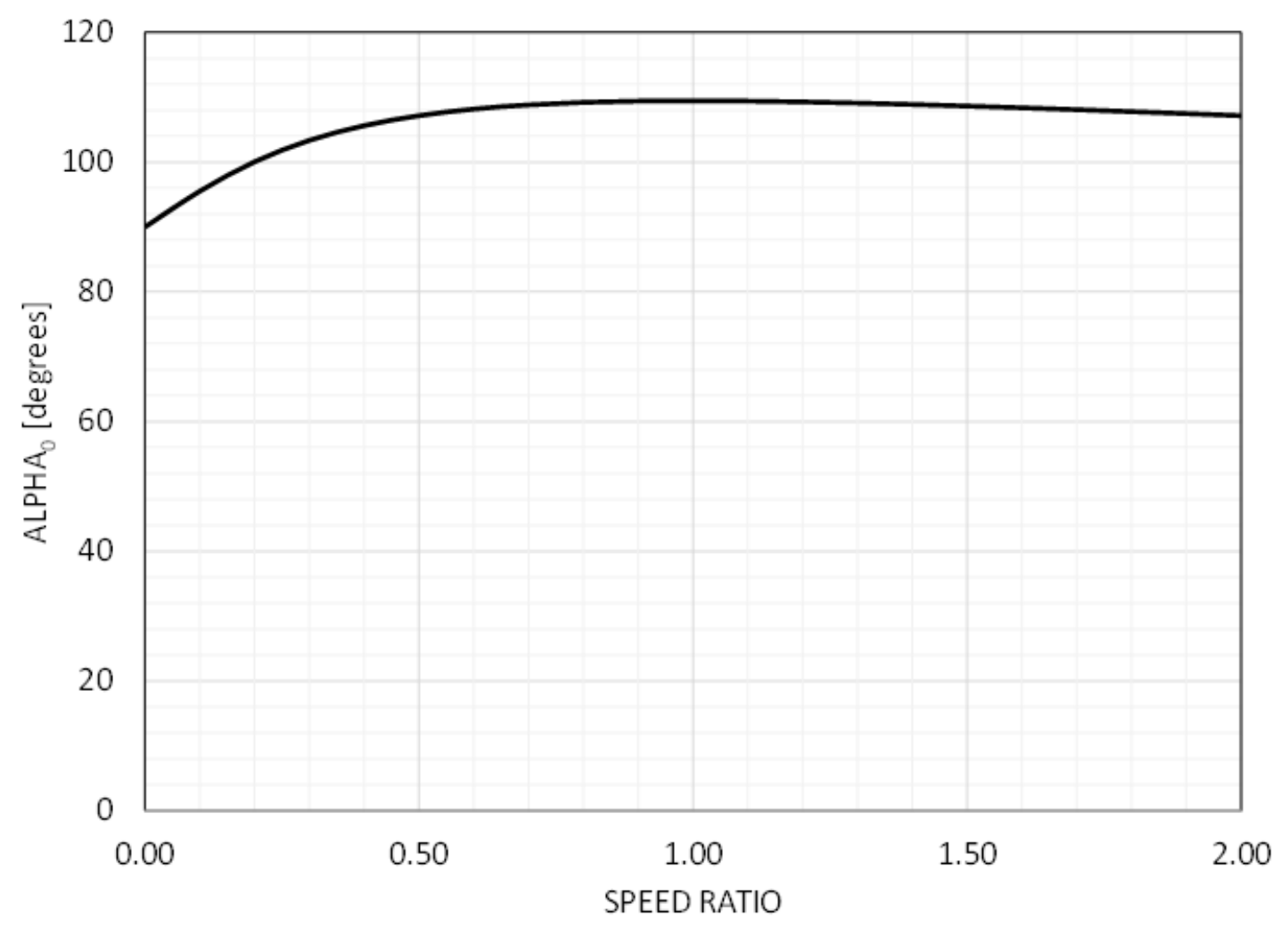

Figure 5 Optimal wind angle versus ship-to-wind speed ratio.

It is instructive to take a closer look at each term in the force balance equation with $\rho$ as the air to water density ratio

$$
\sin B c_{L} \rho\left(s^{2}+1-2 s \cos \alpha_{0}\right)=s^{2} c_{D} a_{V}+s^{2}\left(1-\zeta^{2}\right) a_{T}
$$

where the left-hand term represents the thrust coefficient, the first term on the right-hand side the friction coefficient and the second term the turbine drag coefficient. All drag contributions except the turbine drag are lumped together into the friction drag coefficient, i.e., the induced drag of the sail or wing, the hull drag of the ship, the drag of the foils needed for pitch and heel stability, and the drag of the foils in the case of hydrofoil boats.

Dividing by $\rho$ and replacing the axial induction factor $\zeta$ by the axial velocity ratio $a=v / V$ (used by Glauert [18]) and noting the relation $\zeta=1-2$ a yields

$$
\sin 6 c_{L}\left(s^{2}+1-2 s \cos \alpha_{0}\right)=(1 / \rho) s^{2} c_{D} a_{V}+(4 / \rho) s^{2} a(1-a) a_{T}
$$

In Figure 6 the thrust and the friction drag coefficients are plotted as a function of boat speed (expressed as the boat to wind speed ratio). It is seen that the friction drag increases more rapidly with increasing boat speed. The maximum speed of the boat without turbine therefore is obtained by the crossing of the two curves, which occurs at a speed ratio of 0.8 for a wetted area ratio of 0.4 and a friction drag coefficient of 0.01 . 


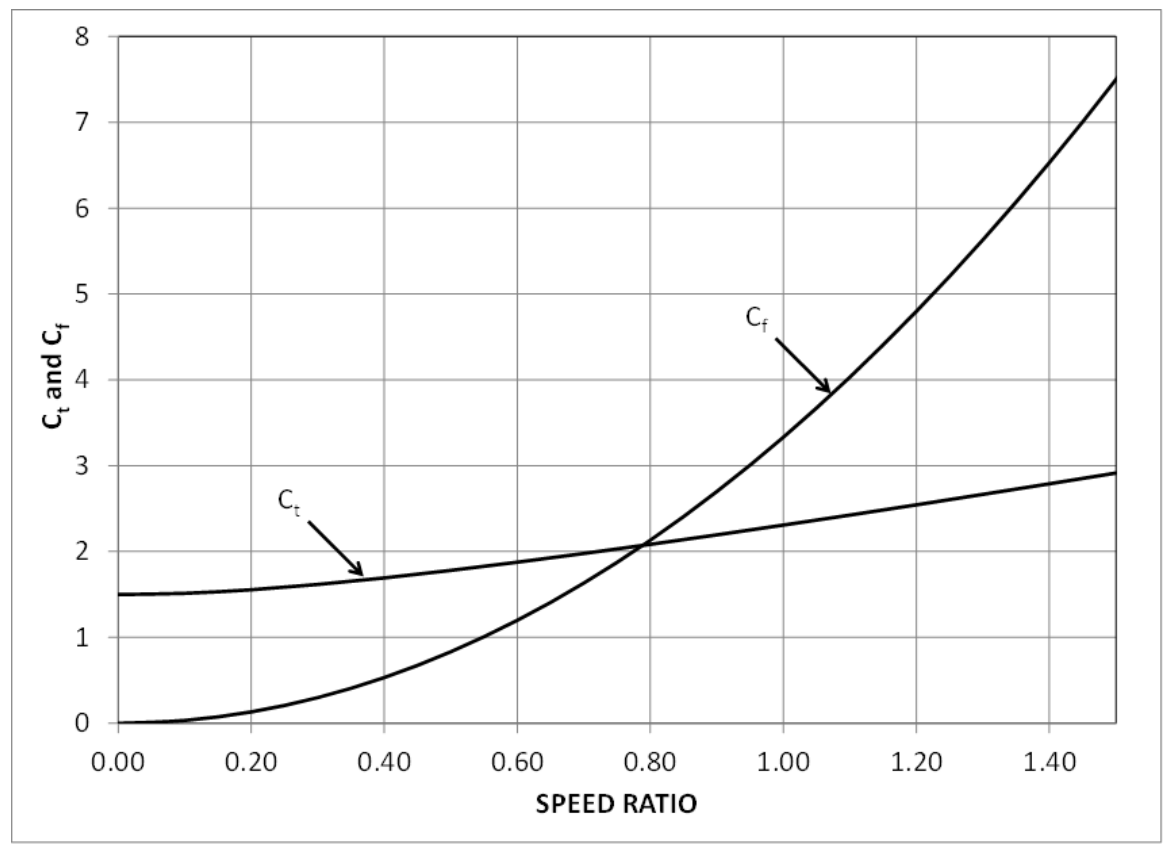

Figure 6 Thrust $\left(C_{t}\right)$ and Friction $\left(C_{f}\right)$ coefficient versus ship-to-wind speed ratio.

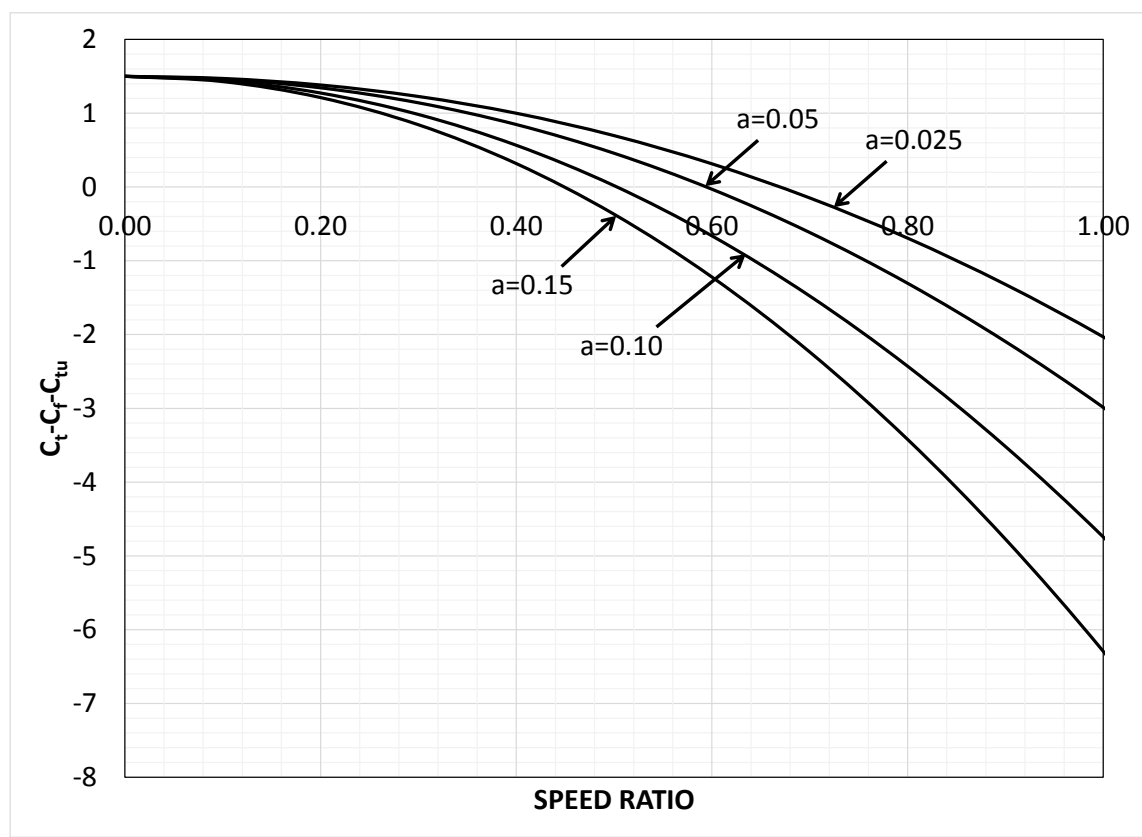

Figure 7 Force balance as a function of a-value.

It is well known from Betz's analysis [19] that the power output from stationary turbines is a maximum for $\zeta=1 / 3$ or $a=1 / 3$. In contrast, the amount of power extraction from a moving turbine must be adjusted in such a way that the boat can move at the optimum speed. This is demonstrated in Figure 7. Here the friction and the turbine drag coefficients are subtracted from the thrust coefficient, plotted for $a=0.025,0.05,0.1,0.15$ as a function of the sip-to-wind speed ratio. Force balance occurs when the sum of the three terms equals zero at the crossing with the $x$-axis. Pelz et al [10] defined a coefficient of performance for moving turbines as the ratio of the turbine output and the available power flowing through the sail area. This coefficient, rewritten in terms of the a-coefficient, becomes 


$$
C_{p}=(4 / \rho) a_{t} s^{3}(1-a)^{2} a
$$

It is seen to be a product of the ship-to-wind speed ratio cubed and (1-a) ${ }^{2} a$. In contrast, the coefficient of performance for a stationary turbine [18] is given by

$$
C_{p}=(1-a)^{2} 4 a
$$

As is well known $[18,19]$, it becomes a maximum for $a=1 / 3$. In contrast, the optimum occurs for a certain combination of speed ratio and a-value. For the example shown in Figure 7 it occurs for $a=0.1$ at a ship-to-wind speed ratio of 0.5 . This finding is in agreement with the optimum value of $\zeta=0.81$ [10]. The reason for the much smaller a-value for maximum power production can be seen from the equation for the coefficient of performance that contains the third power of the speed ratio. An increase in boat speed necessitates a decrease of the a-value for maximum $C_{p}$.

The turbine power output $P$ is obtained from the equation

$$
P=1 / 2 \rho_{g} c^{3} A C_{p}
$$

For a boat with a wetted area ratio $a_{v}=0.4$ and a turbine area ratio $a_{t}=0.0124$ the optimal coefficient of performance is found to be $C_{p}=0.4185$ at a speed ratio of 0.5 . Therefore, the power output of a boat with a sail area of $A=7 \mathrm{~m}^{2}$ sailing at optimal wind angle in a wind of $10 \mathrm{~m} / \mathrm{s}$ becomes 1757.7 Watt. This output reduces to 219.7 Watt in a wind of $5 \mathrm{~m} / \mathrm{s}$. A boat with a sail area of $50 \mathrm{~m}^{2}$ sailing in a wind of $10 \mathrm{~m} / \mathrm{s}$, on the other hand, generates $13 \mathrm{~kW}$ [10]. The power output is proportional to the sail area. Hence, a ship with a sail area of $3200 \mathrm{~m}^{2}$ can be expected to generate about 1-MW. The assumed values of wetted area and turbine area ratios are likely to be conservative. Hydrofoil-borne ships can be expected to generate a significantly larger output.

\section{Small-Scale Technology Demonstrator}

Since no large energy ship has yet been designed, constructed and tested the major technology components are first demonstrated at small scale. To this end, the LASER sailboat shown in Figure 3 is used. It has a length of $1.05 \mathrm{~m}$ and a sail area of $0.485 \mathrm{~m}^{2}$, whereas the full-scale boat has a length of $4.2 \mathrm{~m}$ and a sail area of $7 \mathrm{~m}^{2}$. Since energy ships will have to operate fully autonomously, it is cost effective to demonstrate this technology at first for the model sailboat.by providing it with a sail and rudder controller so that it can operate in an autonomous wind-conversion optimization mode by selecting the boat speed and heading for maximum energy conversion. The necessary components include a Pixhawk 2.1, or Cube, a Davis anemometer for wind direction and speed measurement, a Hitec Optic 5 Receiver for radio control, a Here-2 GPS for global positioning, a Zippy $4000 \mathrm{mAh} 2 \mathrm{~S}$ Li-Po Battery as power source, a sail servo and a rudder servo for sail and rudder control. The sail controller chosen is a commercially available unit known as Pixhawk 2.1. It is run by ArduPilot Rover which is an open-source autopilot software developed for ground vehicles and boats. The firmware is equipped with multiple modes, including manual and auto. Manual control allows the boat to be controlled through an RC transmitter, while auto mode allows the user to input a predefined sailing path. During the autonomous mission, the boat sails to each waypoint, using wind speed and direction information to optimize wind. Additionally, many parameters are available to configure sailing conditions, such as ideal sail angle, PID controller variables, and tacking angle. 
The tests were conducted on Lake McClure in California during the months of June and July 2019. Figure 8 shows the lake and an image during the autonomous operation of the scaled sailboat and its trajectory from one of the test days. McClure Lake has prevailing WNW winds of 2 to $6 \mathrm{mph}$.

In addition, tests on a full-scale LASER boat were conducted to explore the feasibility of measuring the power output achievable with a $7 \mathrm{~m}^{2}$ sail area. To this end, the operation of a hydrokinetic turbine was simulated by the use of two flat plates mounted perpendicular to the flow on both sides of the boat. The plate area was $0.0142 \mathrm{~m}^{2}$. Since the drag coefficient of a quadratic plate is 1.18 , the additional drag caused by the two plates can be estimated. This drag can then be converted into an estimate for the power output of a hydrokinetic turbine that generated the same amount of drag. The tests were conducted in the San Francisco North Bay at a wind speed of $3 \mathrm{~m} / \mathrm{s}$ by measuring the boat speed with and without plates. Addition of the plates caused a reduction in speed from $2.9 \mathrm{~m} / \mathrm{s}$ to $2 \mathrm{~m} / \mathrm{s}$ [20].

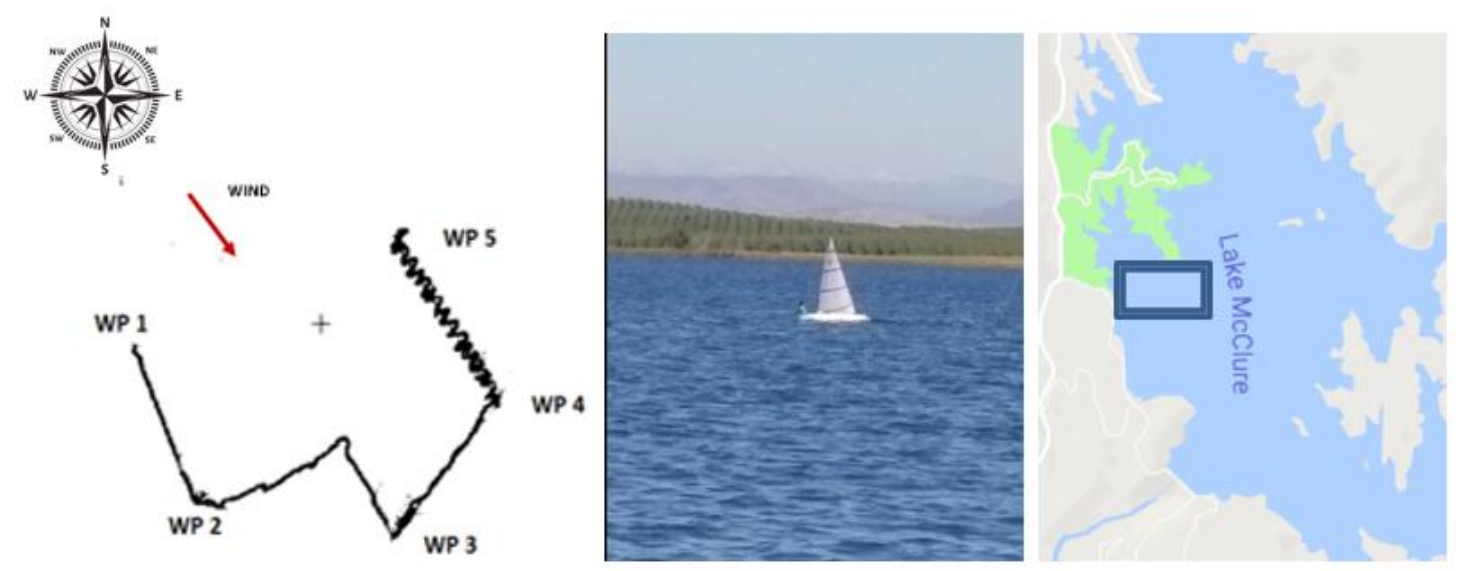

Figure 8 LEFT, autonomously sailed trajectory and pre-planned path Way Points (WP) 1 to 5. Red arrow indicates wind direction during autonomous sail tests. MIDDLE, windward sailing on WP 4 to 5 leg showing the zigzag autonomous sail working properly. Gain adjustment can optimize sailing. RIGHT, Sail test site marked with a rectangular box.

\section{Summary and Outlook}

The global ocean winds offer an energy resource that deserves attention as a possible key to accomplish the dramatic decrease in carbon dioxide emission required to forestall irreversible climate change [5]. The analytical studies, conducted over the past few years [10-17], indicate that high-performance sailing ships equipped with hydrokinetic turbines can produce an electric power output that can either be stored in batteries or converted into storable hydrogen by means of onboard electrolysers. These "energy ships" need to sail at an optimal wind angle at as high a speed as possible. This suggests the use of modern sail technology in combination with hydrofoils to maximize the thrust and minimize the ship drag. In addition, these energy ships need to sail autonomously in order to minimize personnel costs. The basic technology elements can be demonstrated at small scale in order to minimize development costs. The tests described in this paper demonstrated the successful operation of an autonomous navigation and control system installed in a model LASER sail boat. The next step in the planned development plan is the testing 
of an autonomous full-scale LASER boat equipped with a small hydrokinetic turbine. The experience gained with these boats will then be useful to operate sailboats with 30 to $50 \mathrm{~m}^{2}$ sail area to enable power outputs between 10 to $20 \mathrm{~kW}$. Completion of these small-scale tests then will allow the technical and economical assessment of large-scale energy ships.

The current global power need is approximately $18 \mathrm{TW}$, which is projected to increase to about 29 TW by 2050. The transition to sustainable global power generation will require a global engineering initiative to select the technically and economically most feasible emission-free power generation methods [21]. The energy ship concept offers access to virtually limitless energy whose conversion to storable energy requires only the use of readily available technologies. Energy ships with sail areas comparable to areas used on sailing ships in the late 1800 s can produce storable hydrogen, which yields 2 to $3 \mathrm{MW}$ of power after transport to shore. Hence, 10 to 15 million energy ships can satisfy the global power demand. A further important aspect is the fact that in contrast to land or offshore wind turbines energy ships operate in international waters and therefore are not subject to the many regulations and limitations encountered on or close to land.

\section{Author Contributions}

About equally shared, with MFP mostly responsible for the analysis and the writing of the paper, NS mostly for the design and testing of the autonomous sailing.

\section{Competing Interests}

The authors have declared that no competing interests exist.

\section{References}

1. Salomon R. Process of converting wind energy to elemental hydrogen and apparatus therefor. US Patent. 1982; 4335093A. http://www.freepatentsonline.com/4335093.html

2. Meller M. Wind power linear motion hydrogen production systems. US Patent. 2006; 7146918. http://www.freepatentsonline.com/7146918.html

3. Gizara AR. Turbine-integrated hydrofoil. US Patent. 2007; 7298056. http://www.freepatentsonline.com/7298056.html

4. Holder KL. Einrichtung zum Umwandeln von Windenergie ueber dem offenen Wasser, insbesondere Ozean, in elektrische Energie. German Patent. 2008; DE102007057267A1.

5. Platzer MF, Sarigul-Klijn N. A novel approach to extract power from free-flowing water and high-altitude jet streams. Proceedings of the ASME Energy Sustainability Conference; 2009 July 19-23; San Francisco, CA, USA.

6. Kim J, Park C. Wind power generation with a parawing on ships, a proposal. J Energy. 2010; 35: 1425-1432.

7. Siddappaji K, Turner M. Revolutionary geometries of mobile hydrokinetic turbines for wind energy applications. ASME Turbo Expo 2015; 2015 June 15-19; Montreal, Canada.

8. Gilloteaux JC, Babarit A. Preliminary design of a wind driven vessel dedicated to hydrogen production. ASME 36th International Conference on Ocean, Offshore and Artic Engineering (OMAE2017); 2017 June; Trondheim, Norway. 
9. Babarit A, Gilloteaux JC, Clodic G, Duchet M, Simoneau A, Platzer MF. Techno-economic feasibility of fleets of the offshore hydrogen-producing wind energy converters. Int J Hydrogen Energy. 2018; 43: 7266-7289.

10. Pelz PF, Holl M, Platzer MF. Analytical method towards an optimal energetic and economical wind-energy converter. J Energy. 2016; 94: 344-351.

11. Holl M, Pelz P. Multi-pole system analysis (MPSA) - A systematic method towards technoeconomic optimal system design. Appl Energy. 2016; 169: 937-949.

12. Holl M, Rausch L, Pelz P. New methods for new systems - How to find the technoeconomically optimal hydrogen conversion system. Int J Hydrogen Energy. 2017; 42: 2264122654.

13. Holl M, Janke T, Pelz P, Platzer MF. Sensitivity analysis of a techno-economic optimal windenergy converter. $2^{\text {nd }}$ International Conference on Next Generation Wind Energy; 2016 August 24-26; Lund, Sweden.

14. Platzer MF, Sarigul-Klijn N, Young J, Ashraf MA, Lai JCS. Renewable hydrogen production using sailing ships. ASME J Energy Resour Technol. 2014; 136: 021203/1-5.

15. Platzer MF, Sarigul-Klijn N. Aerohydronautical power engineering - Is it the key to abundant renewable energy and potable water?. San Diego: University Readers; 2012.

16. Platzer MF, Lennie M, Vogt DM. Analysis of the conversion of ocean wind power into hydrogen. World Renewable Energy; 2017 July; Congress, Perth, Australia.

17. Platzer MF, Sanz W, Jericha H. Renewable power via energy ship and graz cycle. $15^{\text {th }}$ International Symposium on Transport Phenomena and Dynamics of Rotating Machinery, ISROMAC-15; 2014 February 24-28; Honolulu, Hawaii.

18. Glauert $\mathrm{H}$. The elements of aerofoil and airscrew theory. Cambridge: Cambridge University Press; 1926. pp. 206-207.

19. Betz A. Das Maximum der theoretisch moeglichen Ausnutzung des Windes durch Windmotoren. Zeitschrift fuer das gesamte Turbinenwesen. 1920; 26: 307-309.

20. Platzer MF. Unpublished Data.

21. Platzer MF. On the need for a global engineering initiative to mitigate climate change. Int J Energy Prod Manag. 2016; 1: 155-162.

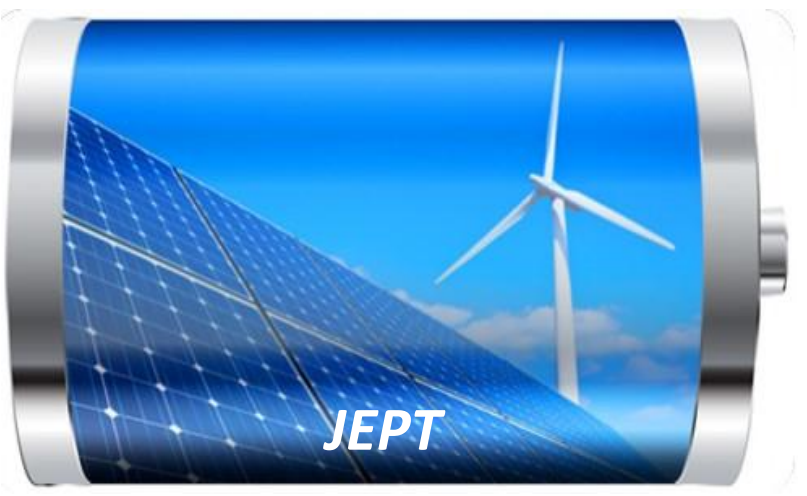

Enjoy JEPT by:

1. Submitting a manuscript

2. Joining in volunteer reviewer bank

3. Joining Editorial Board

4. Guest editing a special issue

For more details, please visit: http://www.lidsen.com/journal/jept 